\title{
Complexities and Challenges of Academic Programme Self-Evaluation: A Case of Two Department
}

\author{
Jacob M Selesho \\ Faculty of Management Sciences \\ Vaal University Technology, Vanderbijlpark. South Africa \\ E-mail:jmselesho@gmail.com
}

Doi:10.5901/mjss.2013.v4n14p175

\begin{abstract}
Recently institutional self-evaluation has become an important management tool implemeted by universities in improving the quality of academic programmes. Compared to earlier decades, not only employers are demanding quality from universities but the goverment is also putting pressure for accountability and improvement. This study is monitoring the use of selfevaluation as a management tool to improve the quality of teaching and learning at undegraduate level. The study did use the documental analyses as data gathering instrument from the two schools selected in a university. The findings revealed that the two case study schools have a mixed quality management porcess with regard to Teaching and Learning approach. The findings did provide the study with an alignment of teaching and learning together with assessment. The study did reveal that quality assessment can only be achieved once quality teaching and learning has taken place. There were a number of lesson learnt in the study for instances linking of teaching, learning and assessment was an eye opener since this takes the quality of teaching and its efficiency and its effectiveness.
\end{abstract}

Keywords: Institutional self-evaluation, teaching and learning, assessment, undergraduate

\section{Introduction}

Self-evaluation may be undertaken at various levels within an institution (i.e. at departmental, school, faculty or institutional level). Self-evaluation is often required before external evaluations or reviews can take place (August 2007). The university can heavily rely on internal self-evaluation for the purpose of improving its quality process; $\mathrm{HEI}$ can organized its quality framework in such a way that the system can still perform its designated task even without external reviews (Boele 2007). Self-evaluation if used appropriately tend to give an insight of strong points and weak points of a programme or institutional process and procedures, and consequently give a practitioner a good start for the formulation of implementation plans for improvement purposes. Once the institution has taken a decision to undertake self-evaluation the next process is to decide on the operational process (ENQA 2005).

The operational process may limit self-evaluation within the institution as we have either internal or external review. Mammen (2003) argues, that self-evaluation and self-assessment in the university's activities, need to focus on the most important purposes of a university; teaching, learning and assessment of students' performance. Tejedor and Garci-Valcarcel (2007), agree with Mammen's ideas by contending that self-evaluation is a mechanism that certifies whether or not the university has achieved its educational objectives. It is this regard that a well focused self-evaluation will give the institution some highlight on the improvement of quality through self-evaluation procedures. While Malicet (1997) concur with the two authors, he mentions that it is important to identify areas to be reviewed in the self-evaluation process, in most cases the piecemeal process would be followed rather than focusing on the whole process.

There appeared to be diverse complexities and the challenges of academic programme self-evaluation (Harvey \& Stensaker 2008).

\section{International Perspective}

\subsection{Complexities of self-evaluation}

The call for institutional evaluation is in most cases linked with the state mechanisms of upholding the institutional accountability, with the academic believe of being micro managed. Therefore, being micro manage simply imply 
conducting the process in the most efficient way, keeping their highest ethical standard as well as value for money (Huusko \& Ursin 2010). In HE, this has been visible in the form of increased competition between employees, the commercialisation of education and research as well as the monitoring of efficiency through the measurement of outcomes of institutions and individual staff members (Deem 1998).

This means that HEl's must undertake an internal review continuously to enable HE refine their focus as well as evaluating areas of improvement. In the twenty first century, tertiary institutions are supposed to be learning organisations. They must constantly interact with their internal and external environments to identify their strengths and weaknesses, and position themselves to be competitive globally. Because of internationalization of tertiary education provision, tertiary education institutions should not limit themselves to only the quality models in their home countries, but must be globally conscious (CHE 2007). One of the practices for ensuring improvements in the quality of tertiary education is institutional self-evaluation. Tertiary educational institutions have been described (Huusko \& Ursin 2010)

If one can minimise the resources used and still produce the desired results, one speaks of an efficient and effective process. There may also be an emphasis on the fair and equal distributions of educational resources (equity) or a specific concern with an economic use of these resources (efficiency). The complexity of the process is that reviewers try to intimate that quality is not inherent in the product or the service but it is connected to the use that the consumers make of the product or service. D'Andrea, Gosling and Scott (2002) refers to quality as an evolving term: what was quality in the past is not quality today and what is quality today will not suffice as quality in the future.

\subsection{Challenges of self-evaluation}

According to Hoffmann (2005) one lesson for improving quality and productivity of HEl's is that an institution interested in improving its performance must achieve its quality target and must then work hard to improve capacity, this is a challenge that many if not all HE find it difficult to adjust to. Gift \& Bell-Hutchinson (2007) argues that, more importantly the right approach and procedure should be the main aim taking into consideration the confidence that public have displayed on the university, with particular reference to economic growth, if HEl's can still with the available resources perfom at the required level this will be commndable. It is a fact that despite the challenges of resources academic must be able to produce quality in their academic work. Indeed, academic quality results from the leadership that develops the best-in-class policy and plans, client and human relations with academic and efficient use of the resources. A positive impact on society results in customer and people satisfaction, supplier and partnership performance, leading to sound academic and operational results (Gift \& Bell-Hutchinson 2007).

It is very much in the interest of the institutions to demonstrate such quality that intends to meet compliances to the government and the public. One way of demonstrating quality to the outside world is by putting self-evaluation systems in place. QA is a concept with an unchallenged position in the discussion around HEl's since the late nineties; QA was developed and implemented in most institutions for example the Ducth institution did embace the QA system in their institution of HE (Woodhouse 2006).

The duration of the academic cycle for re-accreditation is another complex matter for the institutions. If the institution meets all of the requirements, it receives accreditation to run the programme, normally for an initial period of 3 years, after which a reassessment is carried out by the National Accreditation Board before the programme can be reaccredited (Ansah 2010). As good as this accreditation process may seem, because it ensures that an institution has the necessary resources to run an academic programme before it starts, it can neither guarantee continuous improvement, nor produce the quality education that the country needs in order to develop and become globally competitive. Evaluating provision alone is not sufficient to ensure quality, because quality depends on processes and outcomes, not only inputs. Inputs which do not match the processes are unlikely to achieve the planned outcomes (Ansah 2010).

Brennan and Shah (2000) view, 'in sum: there are (at least) as many definitions of quality in education as there are categories of stakeholders, times the number of purposes, or dimensions these stakeholders distinguish'. Scheerens, Glas, and Thomas (2003) state that in actual practice, concerns over quality may relate to a good choice of educational objectives (relevance) or the question whether the educational objectives are actually attained (effectiveness).

The sudden interest of the goverments accountability in HE can be ascribed to the increase of funding universities as well as the growth in the number of students entering $\mathrm{HE}$. In the last decade $\mathrm{HE}$ has undergone enormous quantitative growth in the last decade, massification and high enrolment has been witnessed (CHE 2010). As a results of the high enrolment rate and enormous growth, there was Interest in assuring the quality of education offered to $\mathrm{HE}$ students. 
It is this regard that Malicet (1997) states that the aspect of self-evaluation is not new in HE. Various goverments have been collecting information on the number of student registered as well as the academic staff appointed for financial consideration and the prepartion of the goverment funding to HE. Quality of HE and the need for effective (QA) mechanisms beyond those of institutions themselves are becoming priority themes in national strategies for HE. These strategies are being championed by the notion that university as a knowledge produce should be able to play a significant role towards the Millennium Development Goal (MDGs), while on the other there is a growth of private institutions entering the HE landscape. At the institutional level, increasing demand for accountability by governments, other funders and the public, coupled with the desire to be comparable with the best in-country and internationally is pushing HEls to pay more attention to their QA systems (Materu, 2007).

\section{National Perspective}

Although QA appears to be part of the transformational aspects as per White Paper 3 of 1997, less has been done in some universities in developing a self-evaluation process that would help the HEl's to comply with the White Paper. Hence, QA systems in South Africa refered to as "mixed model" perfomed with the intent to exceed the expectation of the transformational process with regard to accountability and quality improvement. If quality is well conceptualised it can help the country to produce graduates that will fit in the workplace and meet the national goals(Botha, Favish \& Stephenson 2008).

Different mechanisms and procedures were in place in various countries to assist in the enhancement of institutional self-evaluation. In some countries this mechanisms will at a particular point pay a special attention to a particular focus. In South Africa, the HEQC is following a threefold approach, which includes institutional audits, programmere-accreditation, and program accreditation. Given the different process and approaches that are in place in different countries, it is clear that a similar pattern can be observed among other countries (Materu 2007). The process might to ascertain extent start with the self-evaluation with the latter being external verification by the QA agency. It is in this case where a judgment will be passed; this is a rigorous process which produces very important decision that can guide the institution going forward. However, it is important and studies have shown that these process require a highly skilled academics in order to yield results. In some smaller countries the cost of undertaking this exercise becomes too expensive and it had to be abandoned.

\section{Research Methodology}

In order for the researcher to address the research question (see 1) document analysis was used as the most appropriate design. The reason for this was that more in-depth understanding could be obtained as the process is less reactive than any other interactive strategies where the researcher extracts evidence. McMillan and Schumacher (2010:361) confirmed this when they defined document analysis as "a non-interactive strategy for obtaining qualitative data with little or no reciprocity between the researcher and the participant". In this study the self-evaluation report "serve as an immediate practical purpose" by providing detailed accounts of events that unfolded during the interviews that were held with the academics (McMillan \& Schumacher 2010:426). Therefore this study's document analysis denotes the analysis of official documents in the form of self-evaluation reports (2009 \& 2010) of two selected schools, namely the School of Interior Design and the School of Chemical Engineering.

\subsection{Paradigmatic perspective}

The study followed an interpretivist paradigm due to the qualitative approach. The interpetivist paradigm focuses mainly on the individual and set out to understand their interpretation of various systems of their findings. The information gathered from the reports was used to formulate the meaning data generated by the research (see table $1.1 \& 1.2$ ). This main interpretive approach involved attempts to comprehend how institutions academics "construct meaning and explain their worlds" via academic programme self-evaluation (Terre Blanche, Durrheim \& Painter 2006).

\subsection{Mode of research}

In this study a qualitative mode of research was employed, because it is best suited to encourages the researcher to understand the context. This context refer particularlyto the criteria for teaching, learning, assessment and management 
of undergraduate academic programmes during self-evaluation.

\subsection{Data collection techniques}

Data was collected in the form of internal self-evaluation reports of two selected schools as mentioned above. Informed consent for data collection were obtained from the Heads of Department (HOD's) of the two selected schools through the quality assurance office.

\subsection{Data analysis and reporting}

The qualitative data obtained from the internal self-evaluation reports were organised, analysed and presented according to three main themes (i.e. teaching and learning, assessment as well as the management thereof. Then researcher constructed categories for analysis by applying the HEQC criteria for self-evaluation for these above-mentioned three themes. These criteria guided the study in assessing its main focus and where these chuncks or group of data were assembled to make a coherent whole (Cohen, Manion \& Morrison 2010).

\subsection{The study population and sample}

The study was conducted at a university in South Africa as the unit of analysis. According to Brynard and Hanekom (2006:55) "the population of the study refers to a group in the universe which possesses specific characteristics". The population of this study consists of all academic Heads of Department (HoDs) from the two Faculties.

In this study a purposeful convenience sampling technique was applied in selecting the appropriate sample. According to Cohen, Manion and Morrison (2007), convience sampling is described as a process where the researcher select a particular group, in part or whole, at the convience of the researcher. For the purposes of this study, the purposesful convenient sample consisted of two selected HODs, as they have participatedand being the key driversin the previous programme reviews, and therefore gained knowledge, skills and experience of self-evaluation at undegraduate level.

\section{Findings and Discussion}

The only challenge posed by the respondent was the rigid approach used by the university in the examination process. Most if not all programmes were not at a liberty to use discipline based assessment process which is contradictory to the university policy.

The process has forced the tendency to focus on input and process to evaluate if the mechanisms develop by the University for the Assessment, which to a certain extent serve as proxy to academic quality of assessment. This is not surprising given the conceptual and operational difficulties of measuring and benchmarking the student's attainment in the whole institution. Based on this understanding the academic indicated that attempt to establish size one fits all approach have no had much success.

In avoiding not being successful most ph are really scarced picking from the self evaluation reports that they wouldn't like to participate in academic programme re-accreditation process based on the punitive measure attached to the process. A numbered of statements was made with regard to among others, the credibility of the re-accreditation process as well as the constitution of peer reviews.

The Faculty represent just one means by which the university have developed and adopted counteracting mechanisms of its own by which to address the issues of self-evaluation is really uncertainty. In some Schools it was not clear which self-evaluation guidelines they are indeed embracing, everybody was following his/her own approach with regard to the interpretation of the criteria and the management at the programme level.

Academics in this study where compelled to comply with the external evaluation system of the HEQC, while it was not clear on the internal process to be followed in achieving the external compliances, their means towards complying was to a certain extent dramatic. Critique is too central to the academics endeavour to passively accept quality mechanisms in which they have little faith.

Although the criteria were clearly spell out on how the minimum requirement sholuld focus on. It was at this juncture that the researcher felt that the self-evaluation matters is not well cascaded at the academic programmes, furthermore it was quite difficulty for HOD's to manage these units by aligning themselves with a particular alignment of 
self-evaluation. Finally, a conclusion will be made emanating from the discussion of the study.

In seeking to establish the self evaluation approach for the management of quality of an academic programmes. It is crucial to appreciate the complexities associated with monitoring and enhancement of quality education. The complexities of the different perception and expectations by the different stakeholders in determining nature of the resources required and the available one's in creating an enabling education experiences.

\subsection{Leadership and human capacity in the faculties}

One of the lessons from this study is the importance of understanding the human capacity requirements of the faculty processes before putting the system in place. The limited availability of the human capacity needed for effective quality assurance is among the most vexing problems facing quality assurance. It is important that institution must continuously train staff members on the quality issues and provide information in order to assist in building capacity for internal reviews in the form of capacitating peer reviewers. Frequent changes in direction or in the quality of assessment processes could be detrimental to the integrity and legitimacy of the process and the use of unqualified HOD's doing selfevaluation could be fatal to the process.

Adequate management capacity at the schools and programmes area key to the quality of work done at these levels. The need to have a strong dedicated quality assurance unit within each the institution with quality officer assigned to each faculty to be responsible for overseeing implementation of quality improvement activities, and to ensure continuous monitoring and evaluation.

\subsection{Capacity Development}

There is currently no formal training available in this area at institution. For staff possessing little experience with HE QA systems, training should focus on providing exposure to HE QA processes. Such training can be obtained through attending conferences, spending some time in institutions of higher learning, study visits, and in-house writing workshops and seminars on QA topics.

Finally the approach to quality assurance based on a managerial rationality. Good management exercised through central control is seen as the solution to achieving organisational effectiveness and efficiency. Quality is typically understood as 'fitness for purpose' with students being viewed as clients or customers.

As has being said that the HE community have a commitment to the process of internal self-evaluation, the only challenge was the reception of the results particular of the review conducted by the HEQC. The seems to be some challenge in accepting the outcomes of the reviews undertaken by the external reviewers in the form of re-accreditation process. This process can be witnessed by the reviewers undertaken by the HEQC in programme of teacher education.

\section{References}

Augusti, G. 2007. Accreditation of engineering programmes: European perspective and challenges in a global context. European Journal of Engineering Education 32(2):273-283.

Boele , E.B. 2007. Handbook on Internal Quality Assurance for Conservations. Utrecht, AEC Publication.

Bologna Process 2005. A framework for qualifications of the European higher education area. Accessed on 2010 December.

Botha, J., Favish, J. and Stephenson, S. 2008. Quality in Higher Education, 14(1), April. Institutional Audits: A Comparison of the Experiences of Three South African Universities.

Bless, C.; Higson-Smith C. \& Kagee. A. 2007. Fundamental of Social Research Methods an African Perspective. Cape Town: Juta and Company.

Brennan, J. and Shah, T. 2000. Managing quality in higher education. Buckingham: Open University Press.

Brynard, P.A \& Hanekom, S.X 2006. Introduction to Research in Management related field. Pretoria: Van Schaik Publishers.

CHE (Council on Higher Education) 2004a. South Africa Higher Education in the First Decade of Democracy. Pretoria: CHE.

CHE (Council on Higher Education) 2004b. Framework for programme accreditation. Pretoria: CHE.

CHE (Council on Higher Education) 2007. A case for improving teaching and learning in South Africa Higher Education. Pretoria: CHE.

CHE (Council on Higher Education) 2008. Service learning in the disciplines lesson from the field. Pretoria: CHE.

CHE (Council on Higher Education) 2010. Report on the national review of academic professional programmes in education. Pretoria: CHE.

D'Andrea, V., Gosling D. and Scott 2002. HEQC improving teaching and learning project: Report on the need analysis institutional visits. Unpublished report to the CHE.

Deem, R. 1998. New managerialism in higher education: The managment of performanceand cultures in universities. International 
studies in the sociology of education 2(1):47-70.

Du Pre, RH. 2009. The place and role of universities of Technology in South Africa. Durban. Art Printers.

DHE\&T 2010-2015. Strategic Plan 2010-2015 Department of Higher Education. South Africa

Education White Paper 3 1997: A Programme for the Transformation of HE, 1997. Pretoria: Department of Education.

ENQA 2005. Standard and guidelines for quality assurance in the European Higher Education

Gift, S. and Bell-BHutchinson, C. 2007. Quality in Higher Education, Vol. 13, No 2 July Quality Assurance and the Imperatives for Student Experiences in Higher Education: The case of the University of the West Indies.

Harvey, L. \& Stensaker, B. 2006. Quality culture: understanding, boundaries and linkages. Paper presented at 29th EAIR Forum, Innsbruk, Austria, $26-29$ August.

Hoffman, S. 2005. Practice and effects of self-evaluation in the institutional evaluation processes of CNE - A study based on 17 evaluation reports of HE institutions of lle-de-France. Embedding quality culture in HE. A selection of Papers from the ENQA Forum.

Huusko, M. \& Ursin, J. 2010. Why (not) asses? Viwes from the academic department of Finnish Universities. Assessment \& Evaluation in Higher Education. 35(7):859-869.

Malicet, DP 1997. Evaluation and self-evaluation in the French Universities. European Journal of Education 32(2):165-174.

Mammen, K.J. (2003). A study of quality dimensions in the faculty of science of a selected university. D.Ed Theses. Umtata: Walter Sisulu University

Materu, D (2007). Constriction of Knowledge Societies: new challenges for Tertiary Education, Washington DC, Word Bank

McMillan, J.H. \& Schumacher, S. 2010. Research in Education. New York: Pearson Education, United States of America.

RSA DoE (Republic of South Africa, Department of Education) 1997a. Education White Paper 3: A programme for the Transformation of Higher Education, (General Notice 1196 of 1997). Pretoria: Department of Education.

RSA DoE (Republic of South Africa, Department of Education) 1997b. Higher Education ACT, (No. 101 of 1997). Pretoria: Department of Education.

Tejedor, F. and Garcia Valcarcel, A. 2007. In Revista de Educacion. (342): 443-448).

Terre Blanche, M., Durrheim, K. \& Painter, D. 2006. Research in Practice: Applied methods for social sciences. Cape Town: University of Cape Town Press.

Woodhouse, D. 2006: 'The role of QA Agencies in High Education in the 21 ${ }^{\text {st }}$ Century', Keynote to $1^{\text {st }}$ International Conference on Assessing Quality in High Education, Lahore, 11-13 December 2006 